
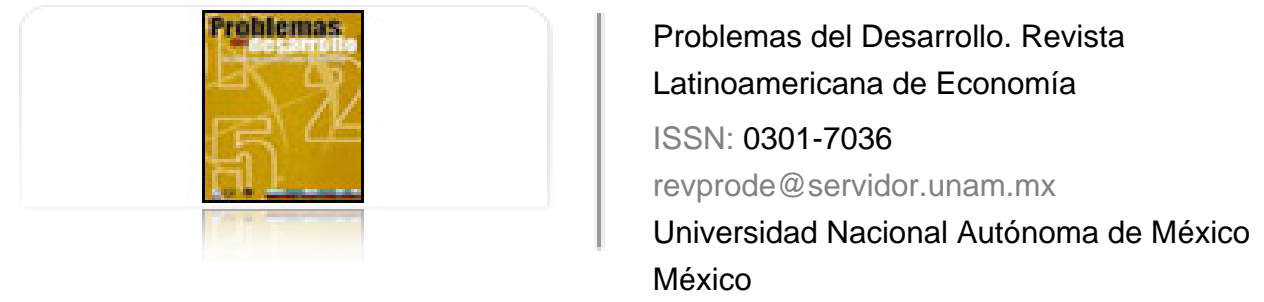

Fernández, Víctor; Lauxmann, Carolina; Tealdo, Julio

Sistema bancario y de producción en Argentina

Problemas del Desarrollo. Revista Latinoamericana de Economía, vol. 43, núm. 170, julio-septiembre, 2012, pp. 69-99

Universidad Nacional Autónoma de México

Distrito Federal, México

Disponible en: http://www.redalyc.org/articulo.oa?id=11823063004

Cómo citar el artículo

- Número completo

- Más información del artículo

Página de la revista en redalyc.org

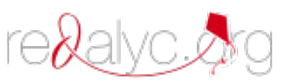

Sistema de Información Científica

Red de Revistas Científicas de América Latina, el Caribe, España y Portugal Proyecto académico sin fines de lucro, desarrollado bajo la iniciativa de acceso abierto 
Revista Problemas del Desarrollo, 170 (43), julio-septiembre 2012

\title{
SiSTEMA BANCARIO Y DE PRODUCCIÓN en Argentina
}

\author{
Víctor Fernández, ${ }^{*}$ Carolina Lauxmann** y Julio Tealdo***
}

Fecha de recepción: 15 de agosto de 2011. Fecha de aceptación: 13 de diciembre de 2011.

\section{RESUMEN}

Los cambios macroeconómicos en la Argentina posteriores a la crisis 2001 abrieron un interesante escenario para indagar si las formas de valorización financiera del capital imperantes durante los años noventa han podido ser reemplazadas por formas acumulativas ligadas a la inversión productiva. Trabajando con el concepto de Sistema Social de Producción (ssp), y su adaptación para su uso en escenarios periféricos, y advirtiendo la importancia que adquiere el Sistema Financiero en dicho sistema, se analiza el Sistema Financiero Bancario argentino durante el periodo 1990-2010. El trabajo identifica la preeminencia de continuidades antes que cambios respecto del periodo de convertibilidad (1990-2001), lo cual afecta limitativamente la cualificación del sSP para insertarse por las vías altas de las cadenas globales y salir de su posición periférica.

Palabras clave: Sistema-mundo, Sistema Social de Producción, Sistema Financiero Bancario, Argentina.

\section{Systems of Banking and Production in Argentina}

\section{Abstract}

Macroeconomic changes in Argentina following the 2001 crisis opened up an interesting panorama for investigating if the forms of financial valuation of capital prevailing during the 1990s have succeeded in being replaced by accumulative forms aligned to productive investment. The Argentine Bank Financial System is analyzed for the period 1990-2010 working with the concept of Social Production System (SPS), its adaptation for use in peripheral regions, and warning of the importance that the Financial System acquires within that system. This study identifies the predominance of continuities before changes in relation to the convertibility period (1990-2001), which partly affects SPS qualifications for entering global networks on a high level, freeing it from its position on the periphery.

Key Words: World-system, Social Production System, Bank Financial System, Argentina.

* Investigador-docente de la Universidad Nacional del Litoral, Argentina y Director del Instituto de Investigación Estado, Territorio y Economía (IIETE). Correo electrónico: rfernand@fcjs.unl.edu.ar

** Investigadora del Instituto de Investigación Estado, Territorio y Economía, Universidad Nacional del Litoral, Argentina. Correo electrónico: claux@unl.edu.ar

*** Coordinador Académico del Instituto de Investigación Estado, Territorio y Economía (IIETE), Universidad Nacional del Litoral, Argentina. Correo electrónico: jctealdo@fcjs.unl.edu.ar. 
Víctor Fernández, Carolina Lauxmann y Julio Tealdo

\section{SYSTÈMES BANCAIRE ET DE PRODUCTION EN ARGENTINE Résumé}

Les changements macroéconomiques en Argentine après la crise de 2001 ont ouvert un champ d'étude intéressant pour examiner si les formes de valorisation financière du capital en vigueur durant les années 90 ont pu être substituées par des formes accumulatives liées à l'investissement productif. Sur la base du concept de Système Social de Production (sSP), et son adaptation à un usage sur des terrains périphériques, et à partir du constat de l'importance qu'acquiert le Système Financier dans ledit système, il est effectué une analyse du Système Financier Bancaire argentin durant la période 1990-2010. Ce travail permet de discerner la prééminence de continuités plus que de changements par rapport à la période de convertibilité (1990-2001), laquelle affecte limitativement la capacité du ssp de s'insérer par les hautes voies des chaînes globales et sortir de sa position périphérique.

Mots clés : système-monde, Système Social de Production, Système Financier Bancaire, Argentine.

\section{SISTEMAS BANCÁRIOS E DE PRODUÇÃO NA ARGENTINA \\ Resumo}

As mudanças macroeconômicas na Argentina depois da crise de 2001 abriram um interessante cenário para se indagar se as formas de valorização financeira do capital, imperantes durante os anos noventa, puderam ser substituídas por formas de acumulaçáo ligadas ao investimento produtivo. Trabalhando com o conceito de Sistema Social de Produção (ssp), e sua adaptaçáo para uso em cenários periféricos, e verificando a importância que adquire o sistema financeiro neste tipo de sistema, se analisa o Sistema financeiro-bancário argentino durante o período 1990-2010. O trabalho identifica a preeminência das continuidades em vez de mudanças, no que diz respeito ao período da conversibilidade (1990-2001), o que atinge a qualificação do ssP para o país se insertar pelas vias altas das cadeias globais e sair de sua posição periférica.

Palavras-chave: Sistemas-mundo, Sistema Social de Produção, Sistema financeirobancário, Argentina.

阿根廷的银行金融系统和生产社会制度：1990-2010年间的连续性与变化 摘要

在2001年危机之后，阿根廷的宏观经济变化对研究20世纪90年代金融资 本增值主要形式被与生产性投资相关联的积累形式所取代, 提供了一个有 趣的情景。本文利用社会生产系统（SPS）概念并将之应用到外围国家情

况, 同时强调该系统中金融体系的重要性，由此分析了1990至2010年间 阿根廷的银行金融体系。针对可兑换法令实施期间（1990-2001年）的变 化, 本文确定了连续性的突出作用, 但对社会生产系统嵌入到全球生产网 络从而结束外围地位的影响比较有限。

关键词: 世界体系，社会生产系统，银行金融系统，阿根廷 


\section{INTRODUCCIÓN}

La pervivencia de un sistema-mundo capitalista jerárquico y estratificadamente organizado en centro, semiperiferia y periferia (Wallerstein, 2004), prácticamente inalterable durante los últimos dos siglos, así como la existencia de excepcionalidades que muestran alguna movilidad ascendente dentro de dicha jerarquía (Arrighi y Drangel, 1986; Arrighi et al., 2003; Mahutga, 2006), presentan un escenario estimulante para analizar las potencialidades y limitaciones existentes en la periferia latinoamericana en general y argentina en particular para salir de esta posición subordinada dentro de la economía-mundo.

Los casos exitosos de un pequeño cúmulo de países del Este asiático que sobre finales del siglo xx pudieron pasar de la semiperiferia al centro-Japón-o de la periferia a la semiperiferia -Taiwán, Corea del Sur-, demuestran que el desarrollo puede ser más que una "ilusión". ${ }^{1}$ Sobre la base de una implicación estatal estratégica que, entre otros aspectos, logró direccionar el flujo financiero hacia la inversión productiva en determinadas ramas industriales (Johnson, 1987; Weiss, 2003; Woo-Cumings, 1999), estos países han logrado romper con los condicionantes asociados a la realización de actividades de escaso valor agregado al interior de sus ámbitos nacionales y regionales e insertarse por las vías altas en las cadenas de valor globales (CvG).

La periferia latinoamericana, por el contrario, implementó durante las últimas décadas del siglo pasado políticas de claro corte neoliberal que, sobre la base de la apertura y desregulación de los mercados, incentivaron las prácticas de valorización financiera del excedente desvinculadas de la inversión productiva, y produjeron una desarticulación y re-primarización de su estructura industrial (Arceo, 2005).

Argentina, no ajena a dichas prácticas, se convirtió durante la década de los noventa en el poster child (Evans, 2004) de las reformas neoliberales en la región, experimentando a fines de 2001 una de las crisis más importantes de su historia. El alejamiento a partir de 2002 de los postulados del mainstream, y la adopción de políticas económicas de matiz heterodoxo, posicionan al proceso de transición argentino como un interesante caso de estudio para indagar en qué medida el cambio en la estrategia macroeconómica ha alterado el patrón de acumulación de modo de posibilitar su salida de la periferia global. Es decir, para analizar

1 En referencia al difundido y controversial artículo de Arrighi, Giovanni "The Developmentalist Illusion: A Reconceptualization of the Semiperiphery” en William Martin (ed.), Semipheral States in the World Economic, Westport, Greenwood Press, 1990, pp. 11-41. 
hasta qué punto, luego de la crisis de 2001, se han podido desplazar las prácticas dominantes de valorización financiera y revincular la reproducción del capital excedente a la financiación de una inversión productiva asociada a los segmentos de mayor valor agregado y dinamismo de la economía mundial.

Para avanzar, al menos parcialmente, en la realización de dicho análisis recurriremos al concepto de Sistema Social de Producción (ssP) (Hollingsworth, 1998; Hollingsworth y Boyer, 1997), con las adaptaciones y reformulaciones pertinentes para su uso en escenarios periféricos, a fin de dar cuenta de las distintas estructuras y arreglos institucionales que dan forma al sistema capitalista en los distintos espacios nacionales de las periferias, y que dotan de especificidad a los mismos tanto en su morfología como en su desempeño.

La importancia que los desarrollos teóricos han otorgado a la estructura y dinámica del sistema financiero en la conformación de los distintos arreglos institucionales (Zysman, 1983), y la centralidad que han tenido en la performance exitosa de los países del Este asiático (Johnson, 1987; Woo-Cumings, 1999), pero también en el desempeño de la economía argentina, fundamentalmente durante los años noventa, lo convierte en el principal objeto de indagación del presente trabajo. De este modo, a través del análisis de la evolución del sistema financiero bancario argentino durante el periodo 1990-2010, procuramos identificar la existencia de vinculaciones entre sus cualidades estructurales y su dinámica de reproducción, particularmente en la existencia-o no- de conexión con el sistema productivo, y la morfología y el desempeño del ssp.

Para ello procedemos a: $\boldsymbol{i}$ ) establecer ciertas precisiones conceptuales en relación al marco teórico de análisis; ii) introducir la descripción del contexto de transición que se encuentra atravesando la economía argentina; iii) analizar la evolución del sistema financiero bancario en términos de su estructura y dinámica, prestando especial atención a las rupturas y continuidades que se sucedieron en el mismo luego de la crisis de 2001; $\boldsymbol{i v}$ ) indagar sus vinculaciones con el sistema productivo, también en términos comparativos para los periodos 19902001 y 2002-2010, y $\boldsymbol{v}$ ) evaluar las implicancias de este tipo de interacciones en la conformación de un patrón de acumulación que permita lograr movilidad ascendente dentro de la conformación jerárquica de la economía-mundo.

\section{PRECISIONES CONCEPTUAL-METODOLÓGICAS: SISTEMA SOCIAL DE PRODUCCIÓN Y PATRÓN DE ACUMULACIÓN}

Un Sistema Social de Producción (ssp) no es sino una configuración social particular que asumen las distintas instituciones vigentes en un país, entre las que 
se encuentran: el sistema de relaciones industriales; el sistema de capacitación laboral; la estructura interna de las firmas corporativas; las relaciones entre las distintas empresas de una misma o distintas ramas industriales; las relaciones de las compañías con sus proveedores y clientes; los mercados financieros; la estructura del Estado y sus políticas; las costumbres, normas, principios morales, reglas que guían la acción social (Hollingsworth, 1998; Hollingsworth y Boyer, 1997).

Esta particular configuración social tiende a variar en la medida en que cambian las formas en que las distintas instituciones se articulan, dando lugar a distintos modelos de SSP y, en definitiva, a distintos modos de acumular y distribuir el excedente en la sociedad. Pero estos arquetipos no son infinitos, se encuentran acotados por la existencia de un necesario grado de complementariedad entre las diferentes estructuras organizativas que forman las diferentes instituciones del ssp, de modo de lograr una configuración social estable -aunque no eterna- y eficiente -en términos de desempeño económico- (Amable, 2000; Soskice, 1999). Así, por ejemplo, un sistema financiero centralizado -basado en bancos- tenderá a favorecer proyectos industriales con rentabilidad obtenible a largo plazo, para cuya realización se requiere mano de obra especializada. Por el contrario, un sistema financiero descentralizado, con predominio del mercado bursátil será proclive a asistir a un sector industrial fundado en proyectos de rápido retorno de la inversión, complementado con instituciones que alientan competencias genéricas en la fuerza de trabajo (Amable, 2000).

Además de la complementariedad entre los distintos elementos componentes del ssp, existe entre ellos cierta jerarquía, por lo que una o varias instituciones obtienen especial influencia en la determinación de su morfología y desempeño (Amable, 2000).

Diversos desarrollos teóricos han resaltado la importancia del sistema financiero en la conformación de los distintos arreglos institucionales y trayectorias de crecimiento (Zysman, 1983). Pero ha sido la relevancia de este sistema en el proceso de constitución de las complementariedades entre las distintas instituciones que caracterizan a los ssp del Este asiático, y su contribución para romper con las lógicas centro-periferia sobre las que se estructura el sistema-mundo, las que lo tornan un elemento estratégico para el análisis de las trayectorias de desarrollo.

El sistema financiero, y en particular el sistema bancario, ha mostrado ser un elemento determinante en la configuración de los ssp asiáticos exitosos (Johnson, 1987; Woo-Cumings, 1999; Zysman, 1983). Salvaguardando las especificidades nacionales, el Estado ha adquirido en todas estas experiencias un rol central al ejercer, en el marco de una política industrial orientada a estimular el desarrollo, un fuerte control sobre el sistema financiero que le permitió direccionar el crédito ya sea a través de la banca privada, la banca pública o, incluso, en algunos casos 
a través de una banca de desarrollo hacia la inversión productiva en ciertas áreas consideradas estratégicas (Amsden y Euh, 1993; Epstein y Grabel, 2007). De este modo, y conjuntamente con la implementación de un sistema de monitoreo del cumplimiento de los requerimientos de performance estipulados como condición del otorgamiento de los préstamos, estos países han podido conformar un patrón de acumulación endógeno y dinámico -con variantes en cuanto al nivel de concentración- (Fernández, 2010), que les ha permitido acceder por las vías altas a las cadenas internacionales de producción (Arceo, 2005).

La posibilidad de alcanzar esos resultados conlleva entonces, para la periferia latinoamericana, la necesidad de conformar un ssp con un patrón de acumulación endógeno, descentralizado ${ }^{2}$ y dinámico, capaz de revertir los patrones combinados de trasnacionalización, concentración y propensión a la generación de beneficios en forma ajena al aprendizaje y la innovación, que han dominado el escenario argentino en particular (Nochteff, 1996) y el latinoamericano en general (Cimoli et al., 2005). Pero también y fundamentalmente, la necesidad de poner fin a las prácticas de autovalorización del capital financiero y ligar su reproducción a la financiación de una inversión productiva que permita conformar dicho patrón de acumulación. Para ello, procurando lograr cierta coherencia institucional que haga sostenible el ssp, entendemos indispensable que las propiedades estructurales del sistema financiero sean compatibles con las características que se demandan al sistema productivo.

Ahora bien, la observación de estos aspectos -en los que se combinan endogeneidad, dinamismo y descentralización- para las economías periféricas, implica trascender la forma en que el concepto de ssp ha sido originariamente concebido en los países centrales. En aquellos escenarios, el enfoque del ssp se ha concentrado principalmente en el estudio del sistema de relaciones intra e interempresariales y en los distintos mecanismos de coordinación de las mismas, ${ }^{3}$ dando por sentado o desconsiderando ciertas cuestiones de la estructura de capital de las firmas, de la composición de los mercados, de las relaciones cuanti/cualitativas entre las formas financieras y productivas del capital, así como de calidades y formas de intervención del Estado que resultan constitutivas del patrón de acumulación y sus propiedades.

2 La descentralización en la propiedad del capital deviene como una característica deseable para la conformación del ssp en la medida en que la tendencia a la concentración del capital en Argentina y en gran parte de América Latina, ha sido proclive a permitir prácticas rentistas (Nochteff, 2002; Fajnzylber, 1992; Sábato, 1988).

3 Para un análisis detallado de estos mecanismos ver Hall y Soskice (2001); Amable (2000); Hollingsworth y Boyer (1997). 
Pretendiendo entonces establecer un marco de análisis apropiado para escenarios periféricos, y reconociendo la centralidad del sistema financiero bancario en la conformación de los ssp que han podido lograr movilidad ascendente dentro del jerárquico sistema-mundo, así como el predominio de las formas bancarias por sobre las bursátiles en los distintos países de la periferia latinoamericana (Tilteman, 2003), el foco de atención debe centrarse en el estudio del sistema financiero bancario y sus vinculaciones con el sistema productivo. Los aspectos que hay que considerar en dicho análisis, reparando en la necesaria complementariedad enunciada entre la estructura del sistema financiero bancario y del sistema productivo, y atendiendo a las características requeridas a este último para alterar la incorporación subordinada a la economía mundial, comprenden: $\boldsymbol{a}$ ) el grado de endogeneidad o extranjerización de la propiedad del capital del sistema financiero bancario, $\boldsymbol{b}$ ) su nivel de concentración o descentralización y $\boldsymbol{c}$ ) su dinámica de reproducción, prestando especial atención a la existencia o falta de vinculación a este respecto con el sistema productivo.

Teniendo en cuenta las variables recién precisadas, luego de introducir una breve referencia del actual contexto de transición argentino, analizamos el sistema financiero bancario y sus cambios en términos de estructura y dinámica a lo largo del periodo 1990-2010, observando particularmente las rupturas y continuidades que se sucedieron en el mismo con motivo de la crisis de 2001. Evaluamos luego la incidencia de las mismas en su vinculación con el sistema productivo a fin de vislumbrar la existencia -o no- de un cambio cualificador en el ssp argentino que, sobre la base de un patrón de acumulación endógeno, dinámico y descentralizado, permita posicionar competitivamente al país en los segmentos de mayor valorización dentro de las CVG.

\section{DEL MODELO NEOLIBERAL A LA POSCONVERTIBILIDAD}

La década de 1990 en Argentina fue el reinado de las políticas neoliberales. Conforme las recomendaciones del Consenso de Washington (cw) -excepto en la flexibilidad del régimen cambiario-, se llevó adelante una estrategia de disciplina fiscal; reforma tributaria; liberalización del comercio; promoción de la inversión extranjera directa; privatizaciones y liberalización financiera, ${ }^{4}$ en

4 Sobre la base de los preceptos de la teoría económica neoclásica, se buscó liberar a los mercados de la "represión financiera". Para conocer el contexto en el cual se desarrollaron estas ideas, así como cuáles fueron los trabajos más relevantes dentro de este enfoque ver Cibils y Allami (2010). 
orden a procurar una reestructuración de la economía argentina que permitiera insertarla competitivamente en el mercado global y propulsar su crecimiento (Fernández et al., 2005).

Lejos de este objetivo, la estrategia favoreció la desarticulación y desofisticación del tejido productivo (Kosacoff, 2002; Kulfas y Schorr, 2002), al exponer fundamentalmente al sector del pequeño y mediano empresariado a la competencia internacional sin ningún sustento cuali ni cuantitativo del Estado (Fernández et al., 2005). Bajo dicha dinámica, el programa de reformas agudizó los niveles de concentración del capital, al mismo tiempo que la reducción del aparato productivo y la consecuente elevación del desempleo empeoraron las condiciones generales de reproducción social (Basualdo, 2000).

La insostenibilidad de este modelo comenzó a hacerse notoria desde mediados de 1998. La economía argentina inició aquí un periodo de prolongada recesión que desembocó en 2001 en una de las crisis más grandes de la historia reciente, con una caída del producto de aproximadamente el $20 \%$, índices de desempleo superiores al $21 \%$ y niveles de pobreza del $53 \%$. No obstante, fue también dicha crisis y la salida del régimen de convertibilidad a que obligó la misma, las que propiciaron la emergencia de un escenario propenso a la revinculación de la reproducción del excedente económico con la inversión productiva. Pero, ¿̨hasta qué punto las transformaciones sobrevinientes contribuyeron a introducir modificaciones en el sistema financiero bancario y en sus vinculaciones con el sistema productivo?, ¿han propendido a la conformación de un patrón endógeno de acumulación dinámico y descentralizado, capaz de convertirse en motorizador de la economía argentina y de modificar cualificadoramente el ssp? En los siguientes apartados tratamos de dar respuesta a estas interrogantes.

\section{SISTEMA FINANCIERO BANCARIO ARGENTINO. CAMBIOS Y CONTINUIDADES (1990-2001, 2002-2008)}

\section{Evolución de su conformación estructural}

\section{a) Niveles de concentración-descentralización del sistema financiero bancario}

Durante la década de los noventa, el sistema financiero bancario argentino en el marco del proceso de liberalización, desregulación y privatización precitado, sufrió una fuerte contracción a causa de una sucesión de absorciones, fusiones, asociaciones, compras y liquidaciones que resultaron en una reducción neta del total de entidades que lo conformaban. De las 166 instituciones vigentes en diciembre 
de 1991 sólo quedaron 86 a finales de 2001, lo que significó una disminución del $48.2 \%$ del total de entidades bancarias. Respecto al periodo postconvertibilidad, puede observarse que la tendencia concentradora se mantuvo, aunque con menor intensidad que durante la década de los noventa. Sólo subsistieron 64 bancos a finales de 2010 de los 86 existentes a comienzos del año 2002, lo que significó una disminución relativa del número de entidades del 25.6\% (Gráfica 1).

Es importante destacar que dicho proceso de concentración no afectó a los distintos tipos de entidades de manera homogénea, sino que implicó cambios sustanciales en la morfología del sistema financiero bancario que aún perviven en la actualidad, cuestión sobre la que volveremos al final del segundo punto de este apartado.

Gráica 1. Sistema Financiero Bancario

Evolución del número de entidades diferenciadas por tipo

(1991-2010)

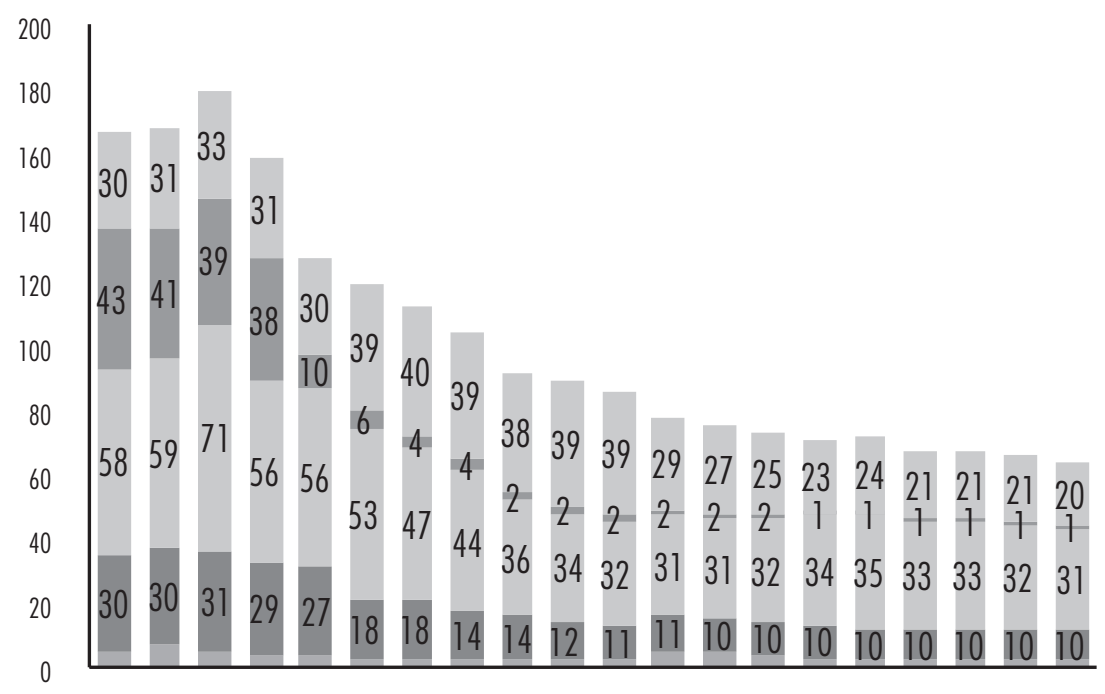

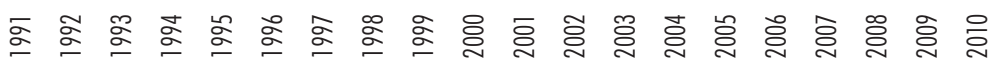

- Locales de capital extranjero y Sucursales de Entidades del Exterior

- Bancos cooperativos

-SA de Capital nacional
- Bancos Públicos Provinciales y

Municipales

- Bancos Públicos Nacionales

Fuente: Elaboración propia con base en la Información del BCRA, Informe de Entidades Financieras. 
La evolución del nivel de concentración del sistema financiero puede observarse también analizando la participación de los diez primeros bancos sobre el total de activos, ${ }^{5}$ depósitos y préstamos a diciembre de cada año. ${ }^{6}$ El análisis de estas variables, una vez más, nos revela un panorama prácticamente sin variaciones luego de la salida del régimen de convertibilidad. Los bancos privados más importantes controlaron durante el periodo 2002-2010 el 45.91\% de los activos totales del sistema bancario, porcentaje que se mantiene casi sin modificaciones si consideramos los últimos ańos de los noventa, en los que promedió el $45.37 \%$. Respecto a la participación en la intermediación financiera, los diez primeros bancos privados con posterioridad a la crisis continuaron desempeñando un rol estratégico, captando el $41.81 \%$ de los depósitos y otorgando el $52.68 \%$ del total de los préstamos del sistema bancario en su conjunto (Gráfica 2). No obstante, en este punto cabe resaltar que existió un leve descenso

Grática 2. Participación relativa promedio de los diez bancos privados más importantes sobre el total de activos; préstamos y depósitos del sistema financiero bancario -a diciembre de cada año-

(1996-2001; 2002-2010)

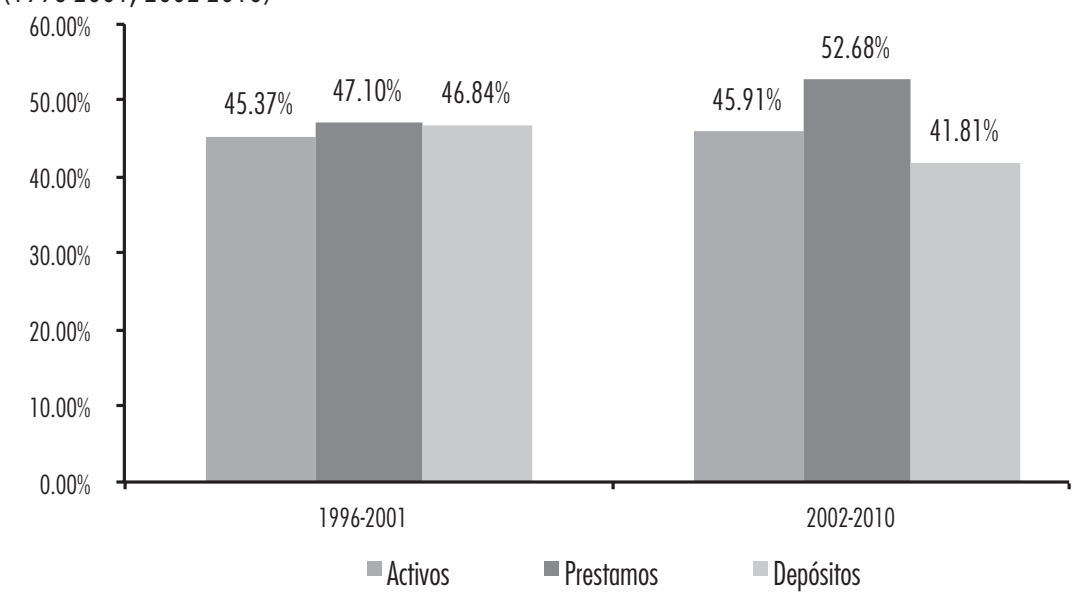

Fuente: Elaboración propia con base en la Información del BCRA, Informe de Entidades Financieras.

5 El principal rubro del activo de las entidades financieras está constituido por los préstamos otorgados, le siguen luego otros activos por intermediación financiera, que incluyen operaciones de pase, operaciones a término de títulos y moneda extranjera, obligaciones negociables, opciones, etcétera, y los títulos públicos.

6 Se acota el periodo analizado en este caso debido a limitaciones de disponibilidad de los datos elaborados por el Banco Central de la República Argentina (BCRA). 
en su participación sobre el total de depósitos con relación al último quinquenio de los años noventa, cuando éstos promediaban el $46.84 \%$. Esta baja de cinco puntos porcentuales puede atribuirse a que luego de la crisis de $2001 \mathrm{el}$ Flight to Quality de los fondos de los ahorristas se produjo hacia la banca pública (Marshall, 2007).

\section{b) Endogeneidad o exogeneidad en la propiedad del capital}

Sobre el origen de la propiedad del capital, también han operado cambios durante la década de 1990, principalmente a partir de 1995-1996 cuando tuvo lugar un marcado proceso de extranjerización del sistema financiero bancario argentino. La sanción del Decreto $\mathrm{N}^{\circ}$ 146/94 que otorga a los bancos extranjeros el mismo tratamiento que a los bancos locales, y el endurecimiento de las medidas prudenciales y de supervisión sobre entidades financieras implementadas con posterioridad a la crisis del tequila, colocaron a los bancos extranjeros en mejor situación que a los bancos locales. ${ }^{7}$ Este proceso alcanza su cenit en el año 2001, cuando las entidades bancarias de capital extranjero representaban aproximadamente $45 \%$ del total del sector, aunque, también, el inicio de su decadencia, disminuyendo su participación en 14 puntos porcentuales para principios de 2010.

El fenómeno de la extranjerización del sistema bancario también se evidencia en el grado de control de los bancos de capital foráneo sobre las principales variables del mismo: activos, préstamos y depósitos, consideradas a diciembre de cada ańo. Ciertamente, durante la segunda mitad de la década del noventa las entidades financieras internacionales se habían convertido en animadoras estratégicas del proceso de intermediación financiera (Fernández, et al., 2005). Pero luego de la crisis de 2001, del mismo modo que lo precedentemente referenciado en términos de número de entidades, su implicación privilegiada en la obtención y recirculación de los flujos financieros fue sopesada por un mayor protagonismo de la banca nacional -tanto pública como privada.

\footnotetext{
No todas las entidades bancarias del Sistema Financiero se encontraban en las mismas condiciones para hacer frente a las regulaciones sobre capitales mínimos; cumplir con los requisitos de liquidez y la necesidad de calificación requeridos con posterioridad a la crisis. Por lo tanto, estas medidas prudenciales de tipo general que parecen afectar de la misma manera a los distintos actores sobre los que recae, en verdad terminaron favoreciendo a un determinado modelo de banco: bancos más poderosos -mayoritariamente extranjeros- que eran los que se hallaban en mejores condiciones de cumplirlas (García, 1995).
} 
Víctor Fernández, Carolina Lauxmann y Julio Tealdo

Gráica 3. Evolución de la participación relativa de la banca extranjera en el sistema financiero bancario

(1991-2010)

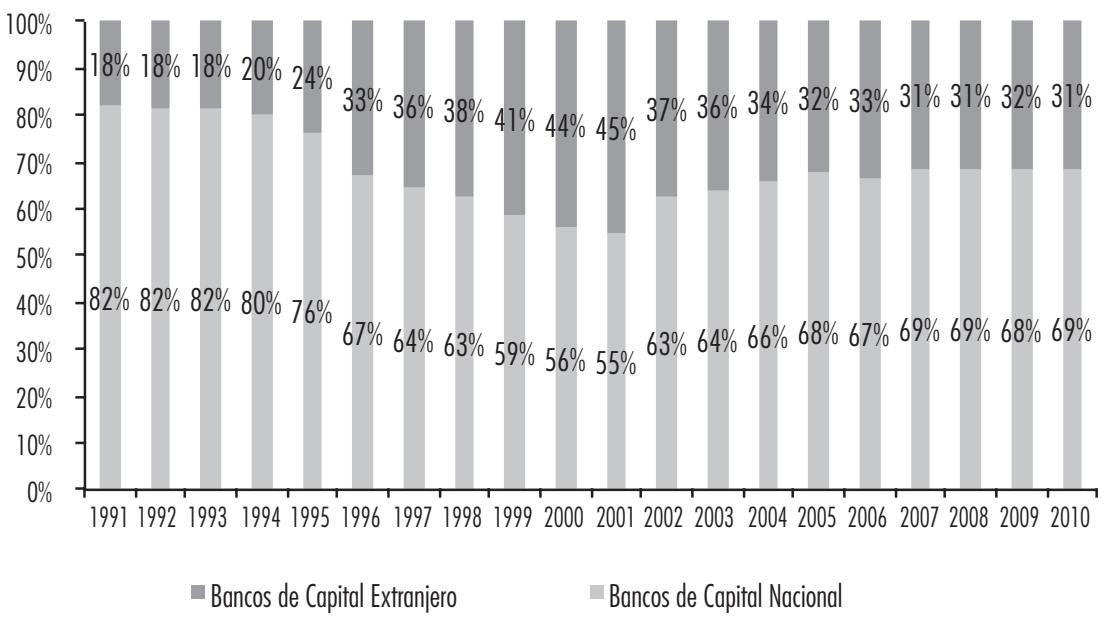

Fuente: Elaboración propia con base en Información del BCRA. Informe de Entidades Financieras.

En este proceso de "renacionalización" del sistema financiero bancario han tenido importancia central las medidas adoptadas por el Estado para salir de la crisis. A diferencia de lo ocurrido en 1995 cuando para paliar los efectos de la crisis del tequila las autoridades gubernamentales optaron por la salida vía "solución de mercado", desimplicándose selectivamente (Fernández, et al., 2005) y favoreciendo a un modelo más extranjerizado y concentrado de banca (García, 199); aquí llevaron adelante una estrategia de intervención activa que propició un cambio en ese patrón. Entre las medidas más destacadas podemos mencionar: la agudización de las restricciones al retiro de efectivo de las entidades bancarias dispuestas en diciembre de 2001; la pesificación asimétrica de los créditos y deudas nominadas en dólares; ${ }^{8}$ la compensación a los bancos con la emisión de letras del Tesoro por esta medida que los perjudicaba, y la reforma de la Carta Orgánica del BCRA que le otorgaba mayor libertad de asistencia a las entidades en riesgo, básicamente a través de una política de redescuentos (Puente y Etchemendy, 2009).

8 Se convirtieron a U\$D $1=\$ 1$, todos los activos de los bancos, y a U\$D $1=\$ 1,40$ todos sus pasivos, actualizables por el Coeficiente de Estabilización de Referencia (CER) y la inflación de los precios al consumidor del mes anterior. 
Este conjunto de regulaciones, en apariencia iguales para todos los bancos, importó una implicación por parte del Estado que benefició a la banca nacional. Las medidas adoptadas, tendientes a evitar la quiebra generalizada del sistema financiero, se encontraban en oposición con los intereses de los grandes bancos trasnacionales. Éstos ofrecían traer dólares desde el exterior y devolver los depósitos hechos en sus entidades en la divisa extranjera, a cambio de quedarse con los bancos privados que no pudieran cumplir con sus obligaciones, y de achicar la banca pública (Marshall, 2007). La desestimación de esta opción, sumada al contexto de crisis que atravesaba Argentina, operó como uno de los factores que desalentó su permanencia en el país (Gráfica 3).

Por lo tanto, podemos concluir que las transformaciones operadas posconvertibilidad tuvieron un marcado sesgo a favor de la banca nacional. Ésta recuperó parte de la participación que había perdido durante los noventa, tanto en términos de número de entidades, como en incidencia sobre los activos, los préstamos y los depósitos totales del sistema financiero bancario (Gráficas 4, 5, 6 y 7$)$.

No obstante es importante señalar que, si bien existe un recupero de posición dentro del sistema financiero por parte de la banca de origen nacional como resultado de los cambios operados a partir de 2002, la estructura del

Gráfica 4. Participación relativa promedio - diciembre de cada año-sobre el total de activos del sistema financiero bancario según el origen de la propiedad del capital (1991-1995; 1996-2001; 2002-2010)

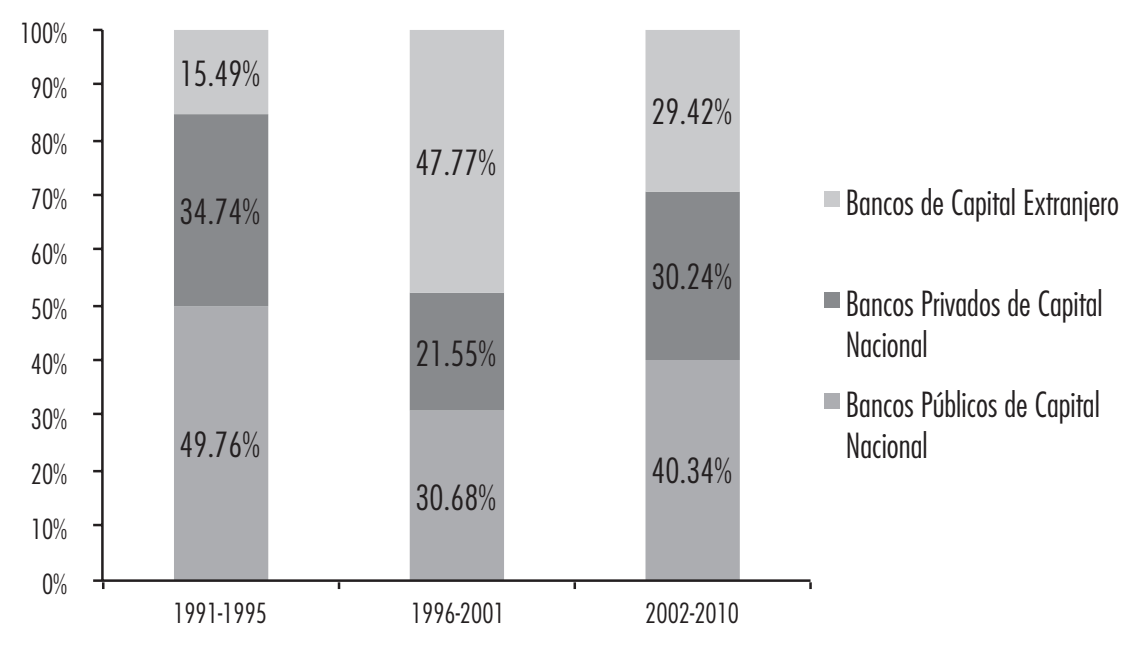

Fuente: Elaboración propia con base en Información del BCRA, Informe de Entidades Financieras. 
Víctor Fernández, Carolina Lauxmann y Julio Tealdo

Gráfica 5. Participación relativa promedio - diciembre de cada año- sobre el total de préstamos emitidos por el sistema financiero bancario según el origen de la propiedad del capital

(1991-1995; 1996-2001; 2002-2010)

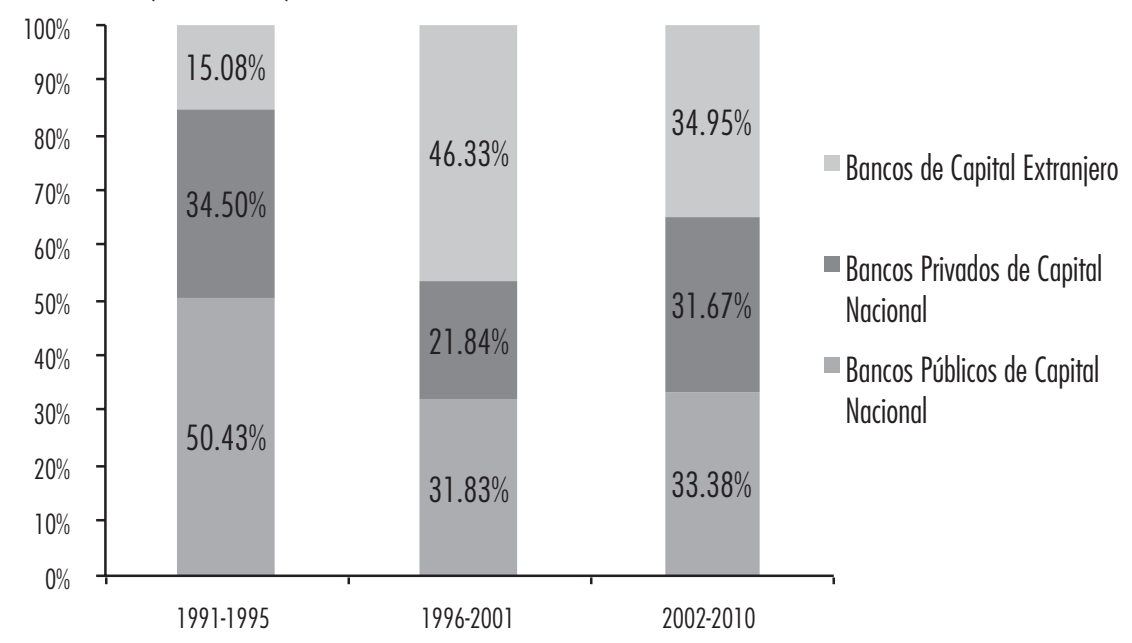

Fuente: Elaboración propia con base en Información del BCRA, Informe de Entidades Financieras.

Gráfica 6. Participación relativa promedio -diciembre de cada año- sobre el total de depósitos captados por el sistema financiero bancario según el origen de la propiedad del capital (1991-1995; 1996-2001; 2002-2010)

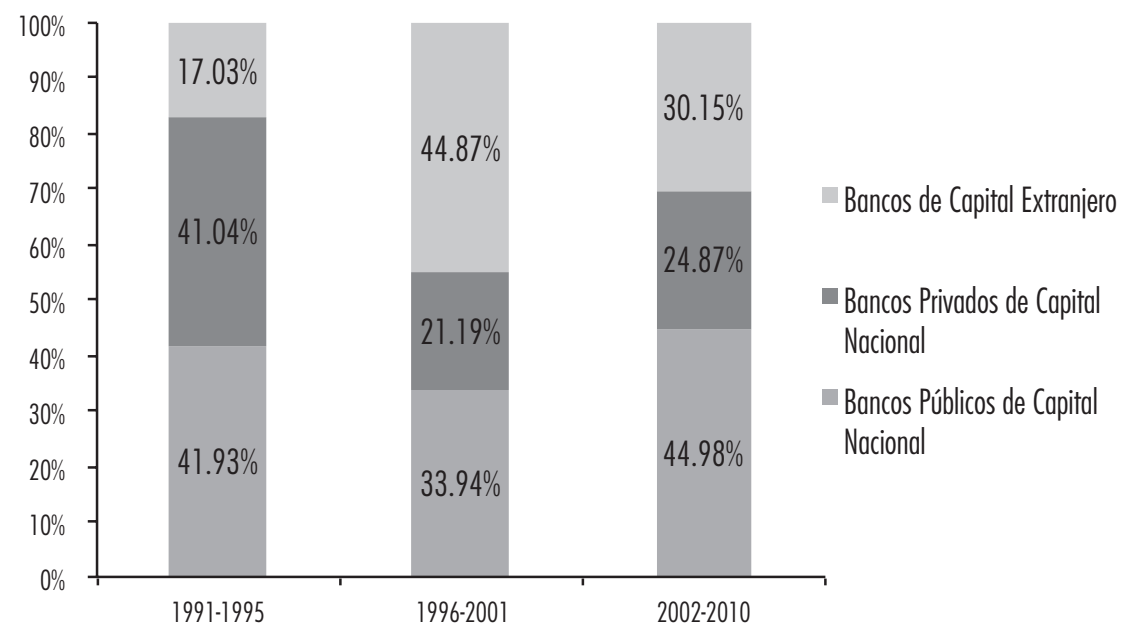

Fuente: Elaboración propia con base en Información del BCRA, Informe de Entidades Financieras. 
sistema financiero bancario argentino en términos de tipo de entidades que lo componen no ha experimentado mayores modificaciones (Gráfica 7).

Los bancos locales de capital extranjero y las sucursales de entidades del exterior 9 que para el periodo 1996-2001 representaban el 39.41\% de las instituciones bancarias, con la salida del régimen de la convertibilidad mantuvieron el segundo lugar dentro del sistema financiero, aunque disminuyendo su participación al 33.21\%. La banca privada nacional mantuvo el liderazgo del sector, incrementando levemente su participación en aproximadamente 4\%. La banca pública, por su parte, continuó ocupando el tercer lugar en el sistema bancario, al que quedó relegada como resultado del proceso de concentración y extranjerización. Sin embargo, no puede dejar de mencionarse el papel relevante que la banca pública ocupa a partir de 2002 en la captación de depósitos, con valores que se acercan al $45 \%$ del volumen total de fondos recibidos, y en la concreción de préstamos, concediendo aproximadamente el 34\% del total de créditos del sistema financiero bancario (Gráficas 5 y 6).

Gráica 7. Participación relativa promedio - diciembre de cada año- de los distintos tipos de entidades del sistema financiero bancario según el origen de la propiedad del capital (1991-1995; 1996-2001; 2002-2010)

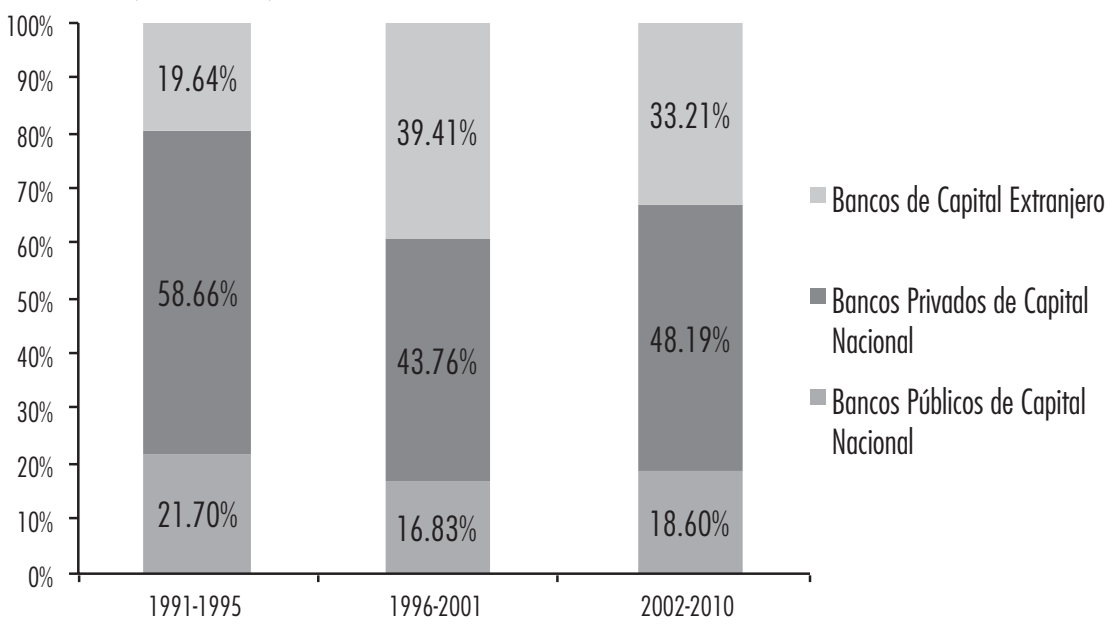

Fuente: Elaboración propia con base en información del BCRA, Informe de Entidades Financieras.

9 Los bancos locales de capital extranjero son aquéllos cuyos paquetes accionarios fueron comprados por bancos del exterior, y las sucursales de entidades del exterior son empresas bancarias establecidas en el país en dependencia directa de sus casas matrices extranjeras. 
Víctor Fernández, Carolina Lauxmann y Julio Tealdo

Ahora bien, estos cambios morfológicos ihan importado alguna modificación en la dinámica reproductiva del sistema financiero bancario postcrisis?

\section{Dinámica reproductiva del sistema financiero bancario y formas de valorización del excedente}

A pesar de estos cambios morfológicos, la dinámica reproductiva del sistema financiero bancario postcrisis parece no haber acusado mayores modificaciones con respecto a la operada en la década de 1990. La evolución del sector, en términos de los valores de la intermediación financiera, continúa siendo más dinámica que la del sector industrial y la economía en su conjunto (Gráfica 8). Cierto es que durante los primeros años del periodo posconvertibilidad la tasa de crecimiento de dichos sectores ha experimentado una cierta nivelación en su evolución con relación el periodo 1990-2001 -cuando la tasa de crecimiento anual de la intermediación financiera se aproximaba al $12.51 \%$, la de

Gráfica 8. Evolución de la intermediación financiera, la manufactura y el Producto Bruto Interno (1990-2010) En Número Índice $1990=100$

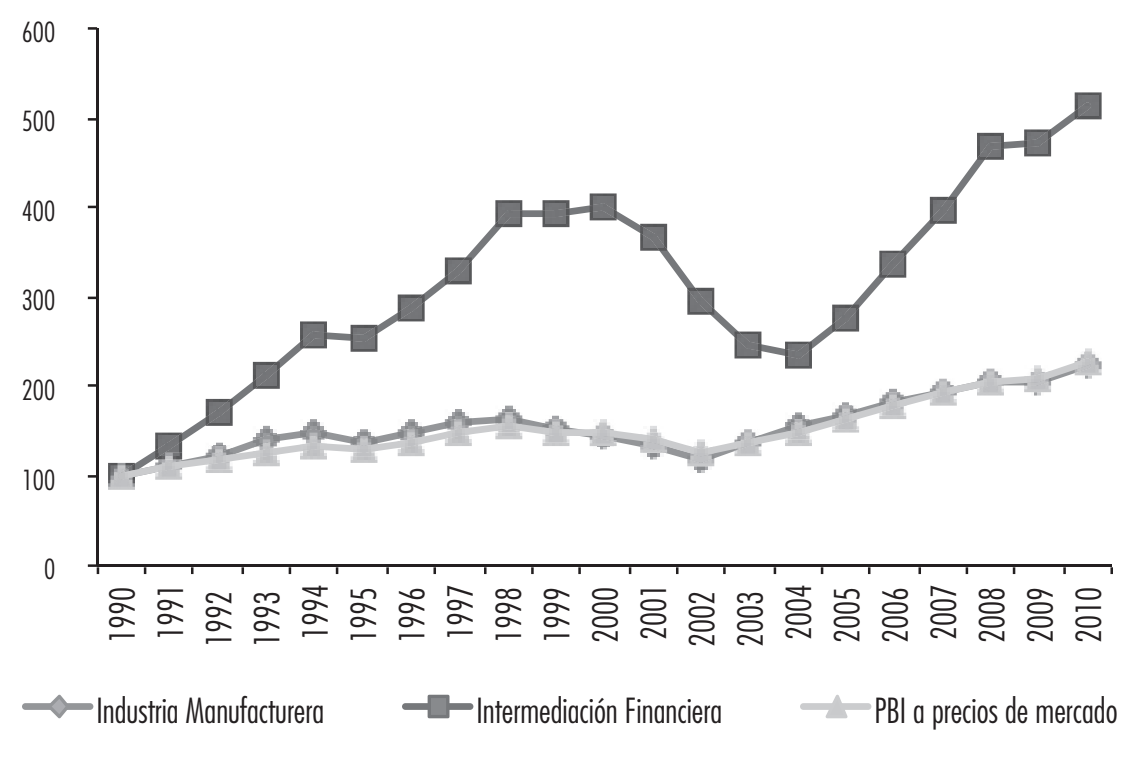

Fuente: Elaboración propia con base en Información del INDEC, Cuentas Nacionales. 
la industria manufacturera era del $2.71 \%$ y la del Producto Bruto Interno del $3.25 \%$. Sin embargo, a partir de 2003 y luego de haber logrado cierta recomposición de los niveles de depósitos y préstamos que permitiera al sistema bancario recuperar su rol de articulador entre los flujos de capital excedente y los posibles destinos de inversión (Damill et al., 2004), comienza a evidenciarse un nuevo despegue del crecimiento de la intermediación financiera. Entre 2004 y 2010, a pesar de la crisis financiera global, aquélla creció en promedio al 13.95\% anual, mientras que las manufacturas y el PBI lo hicieron al 6.23\% y $7.13 \%$ respectivamente, según información de Cuentas Nacionales del Instituto Nacional de Estadísticas y Censos (INDEC).

De este comportamiento diferenciado del sistema financiero bancario se infiere la existencia de cierta capacidad de auto-reproducción, que lo dota de potencialidad para crecer con relativa independencia de la evolución de los demás sectores de la economía. El análisis de la composición de la rentabilidad del sistema financiero adiciona información que refuerza tal presunción de desvinculación de la dinámica de reproducción del sistema financiero de las restantes ramas de la economía. Los servicios -tarjetas de créditos; mantenimiento de cuentas; comisiones vinculadas con obligaciones, valores mobiliarios, garantías; alquiler de cajas de seguridad, operaciones de cambio, entre otros- constituyeron la principal fuente de ingresos de las entidades financieras (30.61\%) durante el periodo 2005-2010. ${ }^{10}$ En segundo lugar se encontraban los resultados por intereses $(26.11 \%)$, pero con una tasa de spread elevada y con tendencia creciente (Cibils y Allami, 2010), y con incremento de la incidencia de créditos personales sobre el total de Préstamos al Sector Privado No Financiero (SPNF) (Allami y Cibils, 2011). Finalmente y en tercer lugar, se localizó la tenencia de títulos públicos (20.35\%) (Gráfica 9).

Este panorama pareciera sugerir que las políticas implementadas para salir de la crisis de 2001, y las consecuencias que ellas han traído aparejadas en la estructura del sistema financiero bancario, no tienden a generar una modificación sustancial en el ssp a partir de un drenaje de flujos desde dicho sistema que dinamice la acumulación productiva. Para avanzar en este análisis, en el apartado siguiente indagamos específicamente la evolución de la relaciones entre el sistema bancario y el sistema productivo.

10 La ausencia de publicación de datos sobre la rentabilidad del sector financiero por parte del BCRA para gran parte de la década del 90 no permite realizar un análisis comparativo a este respecto entre el periodo convertible y el posconvertibilidad. 
Gráifca 9. Composición de la tasa de ganancia bruta del sistema financiero. Participación relativa promedio de los distintos rubros $(2005-2010)$

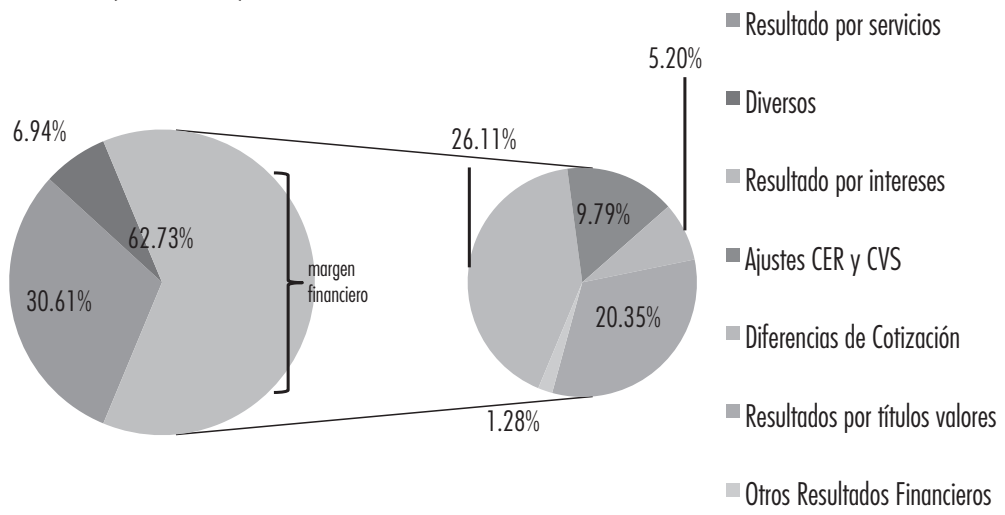

Fuente: Elaboración propia con base en información del BCRA, Informe sobre Bancos.

\section{EL SISTEMA FINANCIERO BANCARIO ARGENTINO Y SUS VINCULACIONES CON EL SISTEMA PRODUCTIVO. IMPLICANCIAS PARA LA CONFORMACIÓN DE UN PATRÓN DE ACUMULACIÓN ENDÓGENO, DESCENTRALIZADO Y DINÁMICO}

\section{¿(Re)direccionamiento del crédito hacia la actividad productiva?}

En la década de los años noventa, como se mencionara anteriormente, la adopción de las recetas del Cw para procurar sanear los males de la economía argentina dieron lugar, entre otras medidas, a una fuerte liberalización del sistema financiero. Los representantes del mainstream creían que la eliminación de intervenciones permitiría elevar la eficiencia del sector no sólo reduciendo la estructura de costos, mejorando la organización operacional, introduciendo nuevas tecnologías y productos financieros, cualificando al personal, etcétera, sino también dejando que el mercado fuera el que determinara el destino del crédito conforme un criterio de evaluación individual, con lo que se podría evitar el drenaje de fondos hacia actividades improductivas (Bleger y Borzel, 2004). ${ }^{11}$

11 Situación que era más propensa a ocurrir con anterioridad a la adhesión de las normas de Basilea, cuando la evaluación del riesgo se realizaba considerando la cartera en su conjunto y el financiamiento podría administrarse entre distintas actividades productivas y zonas geográficas (Titelman, 2003). 
En este contexto, sólo las empresas de primera línea tuvieron acceso preferencial al crédito, mientras que las pequeñas y medianas empresas (PyMEs) $-90 \%$ del parque de establecimientos económicos del país- quedaron desplazadas de cualquier posibilidad de asistencia financiera ${ }^{12}$ (Fernández, et al., 2005; Azpiazu, et al., 2001).

Por otra parte, el financiamiento bancario estuvo orientado principalmente al consumo y al sector servicios, mientras que la actividad manufacturera quedó relegada (Gráfica 10). Esta situación agravó aún más el deteriorado estado del tejido industrial argentino, principalmente a nivel de las pymes (Azpiazu y Schorr, 2010), fuertemente afectadas, como ya indicáramos, por las dificultades para el acceso al financiamiento.

Con posterioridad a la crisis de 2001 y ante una participación más activa del Estado en la economía a través de medidas que tendían a generar cierto estímulo a la actividad industrial -fundamentalmente la fijación del tipo de cambio-,

Gráfica 10. Participación relativa promedio de los distintos sectores de actividad económica sobre el total de préstamos

(1991-2001; 2002-2010)

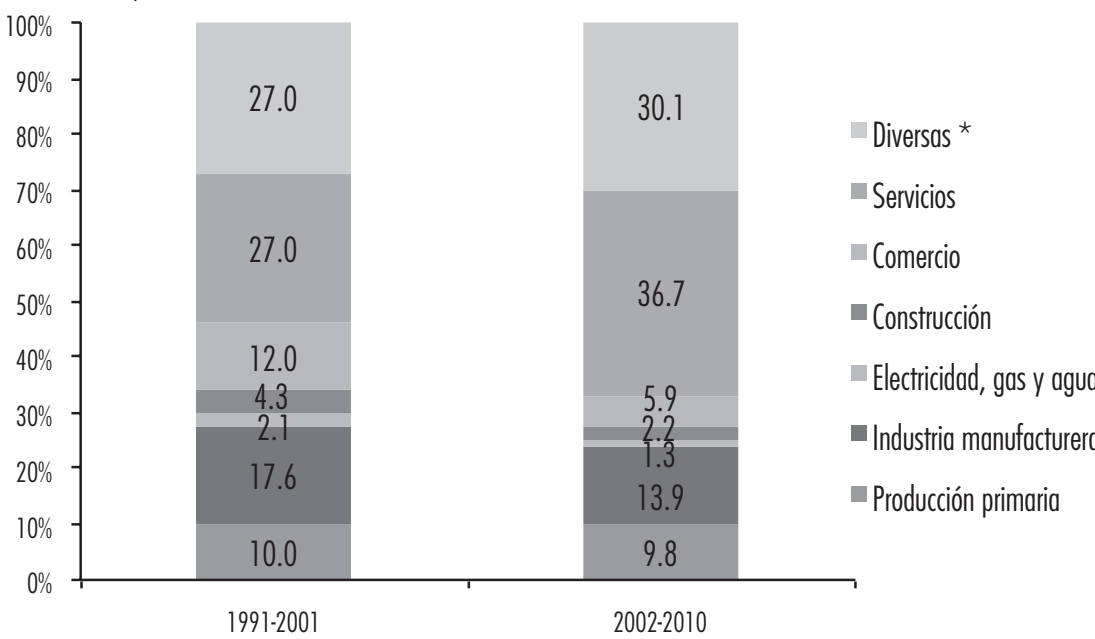

* Incluye préstamos a actividades no identificadas, así como a personas en relación de dependencia laboral. Fuente: Elaboración propia con base en Información del BCRA, Préstamos por Actividades.

12 Además, los grandes grupos económicos -nacionales y extranjeros- también podían obtener fondos en los mercados financieros internacionales, lo que tornaba aún más desproporcionada su ventaja sobre el pequeño y mediano empresario (Azpiazu, et al., 2001; Bleger y Borzel, 2004). 
era factible esperar un redireccionamiento de los flujos del sistema financiero hacia la inversión industrial. Sin embargo, como se observa en la Gráfica 10, el porcentaje de crédito concedido al sector manufacturero fue aún inferior que el otorgado durante los años de vigencia del régimen de convertibilidad. De este modo, la escasa vinculación que existía durante la década de los noventa entre el sistema financiero y el sistema productivo se mantuvo, e incluso se agudizó durante la primera década de este nuevo siglo.

Ello, además, en un contexto de reducción de la relación préstamos al SPNF-PBI. La participación promedio de los préstamos sobre el Producto Bruto Interno durante el periodo 2002-2010 disminuyó el 9.30\% en relación al promedio registrado durante la década de los noventa (Gráfica 11).

Vemos así que la escasa capacidad prestable del sistema financiero bancario ${ }^{13}$ y la de captación de una porción poco significativa de la misma por parte del

Gráfica 11. Evolución de la relación préstamos sector bancario-PBI a valores corrientes (1993-2010)

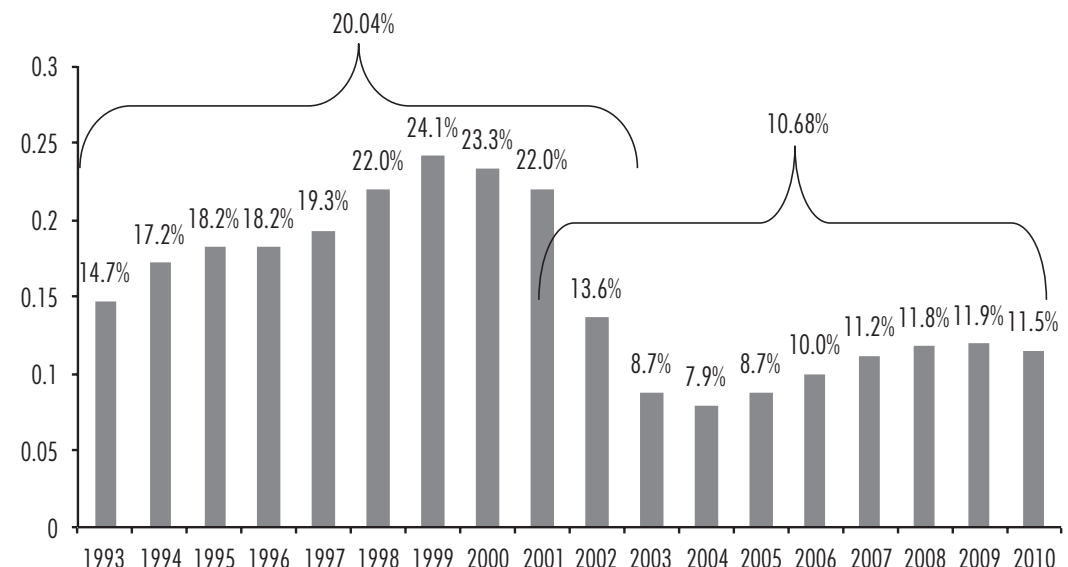

Fuente: Elaboración propia con base en información del INDEC, Cuentas Nacionales y BCRA, Informe de Entidades Financieras.

13 Si bien reviste particular importancia la disminución de la profundidad crediticia del sistema financiero local -nivel de bancarización-, existe aún un hecho de mayor relevancia: su bajo volumen relativo en términos comparados con países desarrollados, e incluso con otros países latinoamericanos. Según las estadísticas elaboradas por el Banco Mundial, mientras que el ratio Créditos al Sector Privado*/PIB argentino apenas era del 13.5\% en 2009, en México alcanzaba el 23.3\%, en Brasil el 54.0\% y en Chile el 97.5\%. Dentro de los países desarrollados, esta relación llega al 165.1\%.

* Incluye los Préstamos al Sector Privado No Financiero, los recursos financieros otorgados al sector privado mediante compra de valores que no constituyen una participación de capital y créditos comerciales y otras cuentas por cobrar. 
sector manufacturero, parecerían corroborar que las transformaciones que sucedieron a la crisis de 2001 y sus efectos al interior de aquél, no tienden a provocar un cambio cualitativo del ssp. Es decir, no se evidencia un apuntalamiento desde el sistema financiero al desarrollo de una actividad manufacturera que permita a la economía argentina insertarse por las "vías altas" en las CVG.

En un intento de profundizar el análisis y obtener mayores precisiones en este sentido, a continuación realizamos un examen del destino sectorial del crédito al interior del sector manufacturero, prestando particular atención al grado de dinamismo de las distintas ramas perceptoras de fondos, así como a la estructura de propiedad de las mismas.

\section{Financiamiento sectorial. Patrones primarios de industrialización, concentrados y extranjerizados vs dinamismo, descentralización y endogeneidad}

Analizando la evolución del financiamiento sectorial a lo largo del periodo bajo estudio, podemos observar que las ramas de alimentos y bebidas y de productos textiles y cuero han sido las principales receptoras de los préstamos destinados a la actividad manufacturera. Durante el periodo de vigencia de la convertibilidad han absorbido cerca del $37 \%$ del crédito industrial, cifra que se incrementó hasta alcanzar casi el 40\% del financiamiento sectorial para 2002-2010. La producción de sustancias y productos químicos, y la fabricación de maquinarias, equipos e instrumentos son las ramas que le siguen en captación de recursos financieros, con un promedio para los años 1991-2001 del $11.23 \%$ y $10.32 \%$ respectivamente, y del 13.09\% y $8.29 \%$ para el periodo postconvertible (Gráfica 12). Estos datos permiten inferir que el perfil de financiamiento a la actividad productiva no dista mucho del que se consolidó durante los noventa. El sistema bancario continúa drenando gran parte de los fondos hacia empresas industriales que desarrollan su actividad al amparo de alguna ventaja comparativa natural o de un "proteccionismo frívolo" (Fajnzylber, 1992), que no permiten la incorporación del país en las corrientes de flujo del comercio internacional en las ramas más dinámicas y de mayor valor agregado

Estas ramas industriales, receptoras de más del 50\% de los flujos del sistema financiero hacia el sector manufacturero presentan, asimismo, en su conformación estructural un elevado grado de concentración. Según datos de la Encuesta de Grandes Empresas (ENGE) realizada por el INDEC, la mayoría de las 500 empresas más importantes de Argentina -en términos de valor agregado- ${ }^{14}$

14 Sin incluir a las firmas con actividad principal Agropecuaria, Financiera y de Servicios Personales. 
Víctor Fernández, Carolina Lauxmann y Julio Tealdo

Gráfica 12. Destino del crédito del sistema financiero al interior del sector manufacturero. Participación relativa promedio del financiamiento recibido por las distintas ramas (1990-2001; 2002-2010)

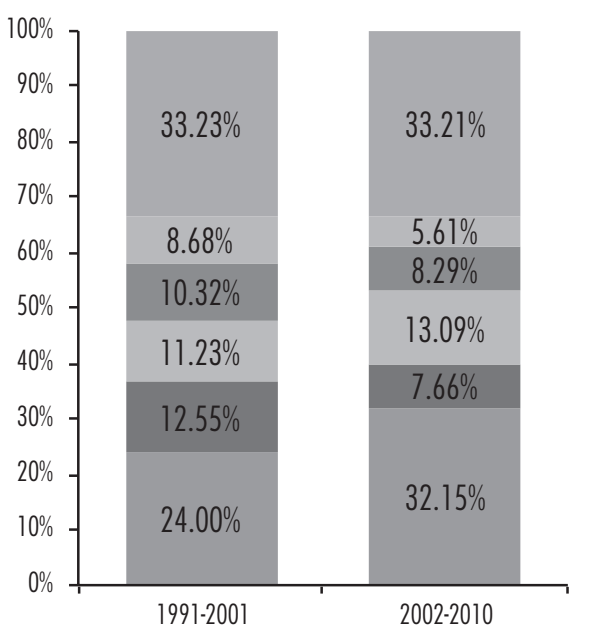

- Otros

- Fabricación de vehículos y equipo de transporte

- Fabricación de maquinaria, equipos e instrumentos

- Fabricación de sustancias y productos químicos

- Fabricación de productos textiles y de cuero

- Elaboración de productos alimenticios y bebidas

Fuente: Elaboración propia con base en información del BCRA, Préstamos por Actividades.

son industriales (Gráfica 13), particularmente de las ramas de alimentos, bebidas y tabaco; combustibles, químicos y plásticos y maquinarias, equipos y vehículos (Gráfica 14).

De este modo y conforme a la información disponible, podemos advertir que las ramas industriales más concentradas de la economía son las mayores beneficiarias de los préstamos del sistema financiero bancario. Si bien los datos resultan insuficientes para concluir que son las grandes empresas las que efectivamente toman crédito del sector bancario, la dificultad de financiamiento de las PyMEs ${ }^{15}$ brindaría elementos adicionales para inferirlo.

15 Conforme a la Ley $\mathrm{N}^{\circ} 25.300$ y sus modificatorias se define a las pyMEs en función del volumen de su facturación. De esta manera, se considera micro empresa a aquélla cuya facturación anual no supera los $\$ 900.000$; pequeña empresa a aquella que encuadra sus ventas entre \$900.001 y \$5.400.000; mediana empresa a aquélla cuyo monto de facturación se encuentra en el rango comprendido entre $\$ 5.400 .0001$ y $\$ 43.200 .000$ y gran empresa a la que supera los $\$ 43.200 .000$. 
Gráfica 13. Ramas de actividad más significativas dentro de las 500 empresas más importantes. Participación relativa promedio (1993-2001 y 2002-2009)

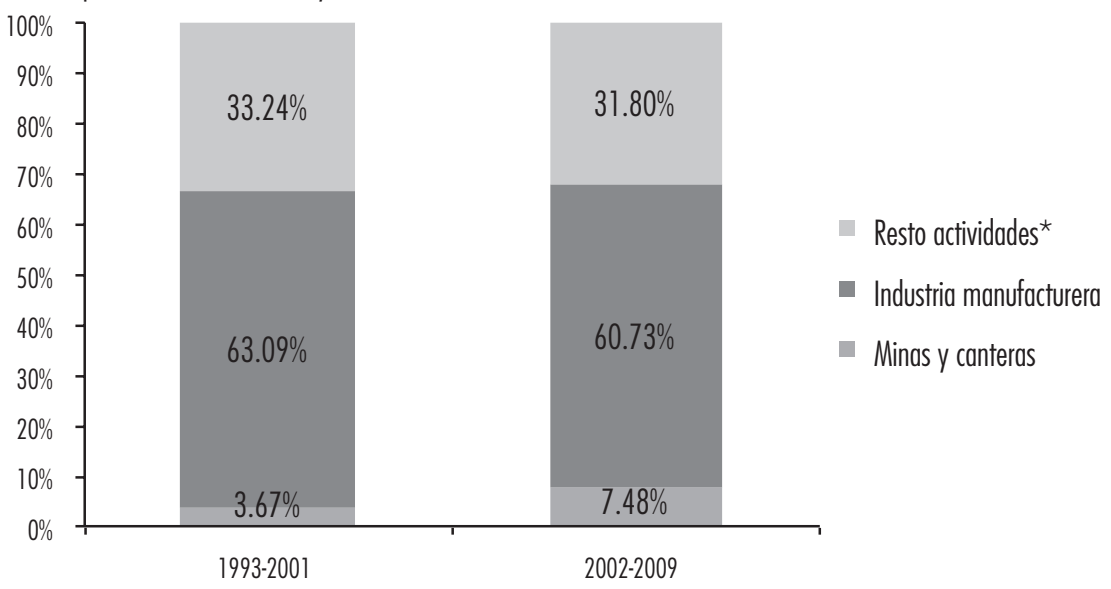

* Dentro de Resto de Actividades se encuentran: Electricidad, gas y agua, Comunicaciones, Construcción, Comercio, Transporte y Otros servicios.

Fuente: Elaboración propia con base en información de INDEC, Grandes Empresas.

Gráfica 14. Sectores más representativos dentro de la industria manufacturera de grandes empresas.

Participación relativa promedio

(1993-2001 y 2002-2009)

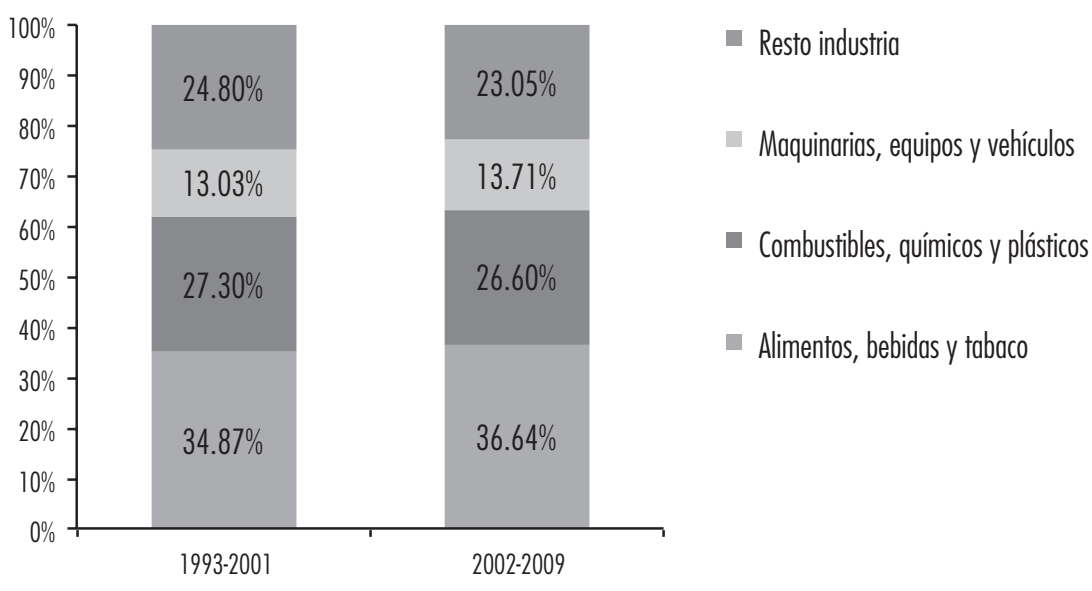

Fuente: Elaboración propia con base en información de INDEC, Grandes Empresas. 
Víctor Fernández, Carolina Lauxmann y Julio Tealdo

La inexistencia de estadísticas precisas para el cálculo del porcentaje de financiación que sobre el total de préstamos del sistema financiero absorbe el sector pyмe, lleva a que recurramos a la metodología desarrollada por García (1996) y posteriormente utilizada por el Centro de Economía y Finanzas para el Desarrollo de la Argentina (CEFID-AR) ${ }^{16}$ a fin de realizar una aproximación razonable del volumen de préstamos concedidos a este tipo de empresas. Analizando la evolución de la financiación a las pymes conforme a dicho criterio, podemos observar que no ha habido modificaciones favorables para el pequeño y mediano empresariado. En el periodo convertible aquél recibía cerca del $20 \%$ del total de créditos del sistema financiero bancario, mientras que en la posconvertibilidad esta cifra no ha llegado al 19\% (Bleger y Borzel, 2004).

Por otra parte, el origen de la propiedad del capital de este núcleo concentrado de empresas es, en gran medida, extranjero. Esta tendencia a la extranjerización del aparato productivo iniciada en los ańos noventa ${ }^{17}$ se mantiene hasta la actualidad, incluso acentuándose dentro de las empresas de la cúpula luego de la crisis de 2001 (Gráfica 5).

La contribución del sistema bancario a la financiación y, en buena medida, a la pervivencia y profundización de una estructura productiva concentrada y extranjerizada, tiene consecuencias poco alentadoras en cuanto a la posibilidad de consolidar un patrón de acumulación dinámico. La experiencia argentina con la Inversión Extranjera Directa (IED) y las Empresas Trasnacionales (ET), en contraposición a ciertos planteos del mainstream, no da cuenta de una mejora en la eficiencia de la economía local y una subsecuente incorporación cualificada en las redes del comercio global. Ha implicado, por el contrario, una profundización de la reprimarización y la inserción subordinada de la Argentina en el mercado mundial. Las filiales extranjeras importan desde sus casas matrices

16 El CEFID-AR realiza una estimación trimestral del préstamo a PyMES a partir de los intervalos de préstamos publicados por el BCRA. A los efectos de llevar a cabo la misma considera pequeñas y medianas empresas a aquéllas cuyos montos de deuda con el sector financiero bancario es superior a los $\$ 500.000$-aunque a partir de 2010 el monto de la cartera comercial asimilable a consumo y los tramos cambiaron, por lo que inicia en $\$ 750.000$ - pero no supera los $\$ 5.000 .000$. Si bien este criterio de estimación puede ser cuestionable dado que, como señala Kulfas (2009), pueden existir grandes empresas que tengan deudas inferiores al precitado monto, es muy poco probable que existan PyMEs que se financien por valores superiores a dicha cantidad. Esta metodología proporciona, así, un criterio razonable para estimar la participación de las pymes en el mercado crediticio, siendo utilizada por diversos autores especializados en la materia (por ejemplo: Cibils y Allami, 2010; Kulfas, 2009).

17 Para una revisión detallada de este proceso ver Basualdo (2000). 
Gráfica 15. Evolución del porcentaje de participación de empresas de capital nacional y extranjero dentro de las 500 líderes. (1993-2009)

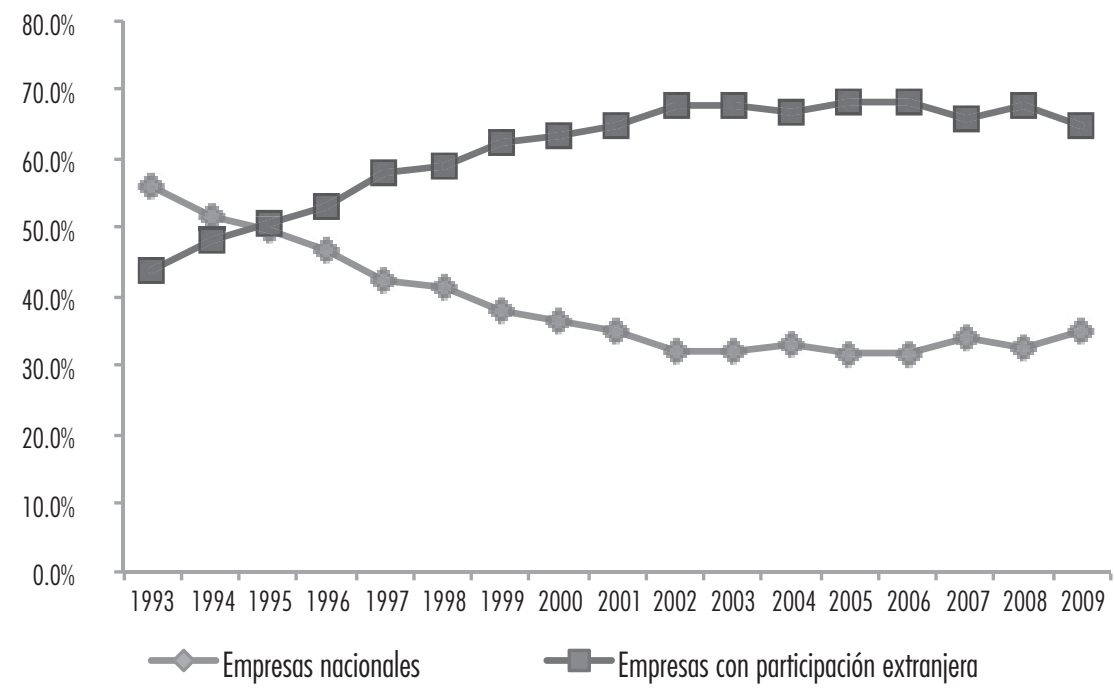

Fuente: Elaboración propia con base en información de INDEC, Grandes Empresas.

los bienes de mayor complejidad tecnológica, desarrollando localmente escasas actividades estratégicas que requieran mano de obra calificada y exportan, principalmente, bienes primarios o manufacturas de uso intensivo de recursos naturales (Chudnovsky y López, 2002). La característica concentrada de la estructura de capital no hace sino reforzar la falta de dinamismo de la estructura productiva, permitiendo a las grandes empresas -locales y extranjeras-, al amparo de un laxo marco regulatorio, abusar de su posición dominante, propiciando prácticas escasamente asociadas al aprendizaje y la innovación, y condicionando el cambio estructural de la economía argentina.

\section{CONCLUSIONES}

Los resultados obtenidos permiten concluir inicialmente que las transformaciones operadas en el sistema financiero bancario argentino luego de la crisis de 2001, tanto a nivel estructural como en su dinámica de reproducción -particularmente en su vinculación con el sector productivo-, no han conllevado un 
cambio cualitativo significativo en el ssp, capaz de orientar a éste hacia un patrón más descentralizado, endógeno y dinámico como el que demanda una inserción menos subordinada a la economía del sistema mundo.

El sistema bancario ha experimentado ciertas modificaciones manifestadas fundamentalmente en una recuperación de la participación relativa de la banca de origen nacional -tanto en términos de activos, como de préstamos y depósitos- fuertemente erosionada durante la segunda mitad de los ańos noventa. Sin embargo dichas transformaciones aún no han podido romper con rasgos estructurales característicos del periodo convertible, fundamentalmente en lo que respecta a niveles de concentración y a la participación relativa del tipo de entidades que lo componen.

La pervivencia de continuidades por sobre rupturas en este sentido -concentración y significativa participación extranjera- se asocia a la inalterabilidad de su performance en el marco del ssp, fundada en la dominancia de formas autoreproductivas con escasa vinculación al sistema productivo, fundamentalmente en sus segmentos más dinámicos.

Efectivamente, el sistema financiero bancario continúa generando el grueso de sus ingresos en actividades con escasa conexión con la financiación productiva, como son la prestación de servicios y la tenencia de títulos públicos. Y si bien una porción no despreciable de sus ganancias es obtenida a través de la intermediación financiera -con elevadas tasas de spread-, gran parte de la misma tiene como principal destino el financiamiento personal, mientras que el crédito a la actividad manufacturera continúa siendo muy restringido.

Por otra parte, los sectores que logran obtener préstamos son los que presentan mayor nivel de concentración y extranjerización y se encuentran especializados en ramas industriales desarrolladas a partir de la existencia de ventajas comparativas naturales, intensivas de trabajo y no requieren mano de obra calificada. No obstante la información analizada no resulta suficiente para concluir que efectivamente sean los grandes grupos económicos trasnacionalizados los que absorben el financiamiento bancario; la dificultad de acceso que presenta la pequeña y mediana empresa a los flujos financieros parecería dar indicios en tal sentido.

De este modo, podemos advertir que no se establece una vinculación entre el sistema financiero bancario y el sistema productivo que tienda a la conformación de un ssp con un patrón de acumulación endógeno, descentralizado y dinámico. En otras palabras, la interacción entre ambos sistemas -financiero y productivo- no favorece el establecimiento de un núcleo de acumulación nacional que, sobre la base de la incorporación de innovación y tecnología, posicione a la economía argentina competitivamente en los segmentos de mayor valor agregado de las CVG, y contribuya por esta vía, a su salida de la periferia global. 
Políticas que avancen en este sentido requieren ser concebidas en el marco de una estrategia integral de desarrollo. Las experiencias internacionales marcan que dicha estrategia guarda en la recuperación de la centralidad del Estado un aspecto fundamental. Para Argentina específicamente, pero también para gran parte de los países periféricos latinoamericanos que, como indicáramos, presentan un ssp constreńido por una estructura productiva fuertemente trasnacionalizada, concentrada y con propensión a la generación de beneficios en forma ajena al aprendizaje y la innovación, esta recuperación del Estado requiere su implicación explícita y estratégica en la promoción de la articulación del sistema financiero bancario con actores locales. Principalmente con aquellos actores dispuestos a desarrollar procesos de aprendizaje -enfrentando los riesgos de la "maldición" de los recursos naturales-, así como los que presentan dificultades para acceder al financiamiento, esencialmente las pequeñas y medianas empresas. Las herramientas con que se cuenta para hacerlo conforme a los estudios de política económica comparada son diversas y comprenden desde la regulación del sistema financiero bancario privado, estableciendo lineamientos y estímulos para el direccionamiento del crédito a sectores y actores específicos, hasta el uso de la banca pública comercial, e incluso la conformación de una banca de desarrollo como complemento para la implementación de una política de desarrollo con base industrial.

Ahora bien, obtener mejoras en las relaciones entre sistema financiero bancario y el sistema productivo dentro una estrategia integral de desarrollo cualificadora del ssp implica, necesariamente, vincular la administración del sistema financiero con otras áreas estratégicas de intervención estatal, como, por ejemplo, las que formulan las políticas industriales. La concreción de ello requiere de un Estado con capacidad para operar esta articulación. El análisis de la capacidad del Estado argentino en este aspecto -como la del resto de los latinoamericanos- podría ser objeto de futuras investigaciones.

\section{BIBLIOGRAFÍA}

Allami, Cecilia; Alan Cibils, "El financiamiento bancario de las pymes en Argentina (2002-2009)", en Revista Problemas del Desarrollo, vol. 165, núm. 42, México, IIEC-unam, abril-junio 2011, pp. 61-86.

Amable, Bruno, "Institutional Complementarity and Diversity of Social System of Innovation and Production", en Review of International Political Economy, vol. 7, num. 4, United Kingdom, Routledge, Winter 2000, pp. 645-687. 
Amsden, Alice; Yoon-Dae Euh, "South Korea's 1980s Financial Reforms: GoodBye Financial Repression (Maybe), Hello New Institutional Restraints", en World Development, vol. 21; num. 3, Great Britain, Pergamon Press, 1993, pp. 379-390.

Arceo, Enrique, "El impacto de la globalización en la periferia y las nuevas y viejas formas de la dependencia en América Latina”, en Cuadernos del Cendes, vol. 22, núm. 60, Caracas, dic. 2005, pp. 25-61.

Arrighi, Giovanni, "The Developmentalist Illusion: A Reconceptualization of the Semiperiphery”, en William, Martin (ed.), Semiperipheral States in the World Economic, Westport, Greenwood Press, 1990, pp. 11-41.

Arrighi, Giovanni; Jessica Drangel, "The Stratification of the World-Economy: An Exploration of the Semiperipheral Zone”, en Review, vol. X, num. 1, Binghamton, Fernand Braudel Center, Binghamton University, Summer 1986, pp. 9-74.

Arrighi, Giovanni; Beverly Silver; Benjamin Brewer, "Industrial Convergence, Globalization, and the Persistence of North-South Divide", en Studies in Comparative International Development, vol. 38, num. 1, Spring 2003, pp. 3-31.

Azpiazu, Daniel; Martín Schorr, "La industria argentina en la posconvertibilidad: reactivación y legados del neoliberalismo", en Problemas del Desarrollo, vol. 41, núm. 161, México, IIEC-UNAM, abril-junio 2010, pp. 111-139.

Azpiazu, Daniel; Eduardo Basualdo, Martín Schorr, La industria argentina durante los años noventa: profundización y consolidación de los rasgos centrales de la dinámica sectorial post-sustitutiva, Buenos Aires, Flacso, 2001.

Basualdo, Eduardo, Concentración y centralización del capital en Argentina en los noventa. Una aproximación a través de la reestructuración económica y el comportamiento de los grupos económicos y los capitales extranjeros, Buenos Aires, FLACSO, 2000.

Bleger, Leonardo; Borzel, Mariano, "La crónica restricción de acceso al crédito de las PYMES argentinas. Diagnóstico y propuestas", en Las PYMES argentinas. Mitos y realidades, ABAPPRA, Buenos Aires, 2004, pp. 243-264.

Cibils, Alan; Cecilia Allami, "El Sistema Financiero Argentino. Desde la reforma de 1977 hasta la actualidad”, en Revista Realidad Económica, núm. 249, Buenos Aires, IADE, enero-febrero 2010, pp. 107-133.

Cimoli, Mario; Gabriel Porcile, Annalisa Primi; Sebastián Vergara, "Cambio estructural, heterogeneidad productiva y tecnología en América Latina”, en Cimoli, Mario (ed.), Heterogeneidad estructural, asimetrías tecnológicas y crecimiento en América Latina, Santiago de Chile, CEPAL/BID, 2005, pp. 9-37. 
Chudnovsky, Daniel; Andrés López, "Estrategias de las empresas transnacionales en la Argentina en los años 1990", en Revista de la CEPAL, núm. 76, abril 2002, pp. 161-177.

Damill, Mario; Nicolás Salvatore; Lucio Simpson, "Diagnóstico y perspectivas del sistema financiero argentino. El sistema financiero de la Argentina bajo el régimen de convertibilidad y la transición a un nuevo modelo de intermediación”, en Documentos del CESPA, Buenos Aires, FCE-UBA, febrero 2004 .

Epstein, Gerald; Illene Grabel, Training Module num. 3. Financial Policy, Brazil, International Poverty Centre, 2007.

Evans, Peter, "Developmental as Institutional Change: The Pitfalls of Monocropping and the Potentials of Deliberation", en Studies in Comparative International Development, vol. 38, num. 4, Winter 2004, pp. 30-52.

Fajnzylber, Fernando, "Industrialización en América Latina. De la "caja negra" al «casillero vacío»", en Nueva Sociedad, núm. 118, abril 1992, pp. 21-28.

Fernández, Víctor Ramiro, "Desarrollo regional bajo transformaciones escalares. ¿Por qué y cómo recuperar la escala nacional?”, en Fernández, Víctor Ramiro y Carlos A. Brandao, (direct.), Escalas y politicas del desarrollo regional. Desafíos para América Latina, Buenos Aires, Miño y Dávila Editores, 2010, pp. 301-341.

Fernández, Víctor Ramiro; Julio Tealdo, Marta Villalba, Industria, Estado y territorio en la Argentina de los 90. Evaluando la desimplicación estatal selectiva y repensando los caminos del desarrollo, Santa Fe, Universidad Nacional del Litoral, 2005.

García, Alfredo, "La financiación hacia PyMEs", en Realidad Económica, núm. 224, noviembre-diciembre 2006, pp. 69-83.

García, Alfredo, "El programa de liberalización financiera en Argentina”, en Minsburg, Naúm y Héctor Valle, (coords.) Argentina hoy: crisis del modelo, Buenos Aires, Ediciones Letra Buena, 1995, pp. 85-106.

Hall, Peter; David Soskice, Varieties of Capitalism. The Institutional Foundations of Comparative Advantage, Oxford, Oxford University Press, 2001.

Hollingsworth, J. Roger, "New Perspectives on the Spatial Dimensions of Economic Coordination: Tensions Between Globalization and Social Systems of Production", en Review of International Political Economy, vol. 5, num. 3, Routledge, Autumn 1998, pp. 482-507.

Hollingsworth, J. Roger; Robert Boyer, Contemporary Capitalism. The Embeddedness of Institutions, New York, Cambridge University Press, 1997.

Johnson, Chalmers, "Political Institutions and Economic Performance: The Government-Business Relationship in Japan, South Korea and Taiwan", en 
Víctor Fernández, Carolina Lauxmann y Julio Tealdo

Deyo, Frederic C. (ed.), The Political Economy of the New Asian Industrialism, Ithaca and London, Cornell University Press, 1987, pp. 136-164.

Kosacoff, Bernardo, "La industria argentina; un proceso de reestructuración desarticulada", en Producción y trabajo en la Argentina. Memoria fotográfica 1860-1960, Buenos Aires, Banco Bice/Universidad Nacional de Quilmes, 2002, pp. 13-31.

Kulfas, Matías "Las pymes argentinas en el escenario postconvertibilidad. Políticas públicas, situación y perspectivas", en CEPAL, Colección Documentos de Proyectos, Santiago de Chile, 2009.

Kulfas, Matías; Martín Schorr, "Sector industrial. La industria argentina posconvertibilidad", en Realidad Económica, núm. 190, Buenos Aires, IADE, agosto-septiembre 2002, pp. 32-52.

Mahutga, Matthew, "The Persistence of Structural Inequality? A Network Analysis of International Trade, 1965-2000", en Social Forces, vol. 84, num. 4, The University of North Carolina Press, June 2006, pp. 1863-1889.

Marshall, Wesley, "La banca extranjera frente a la crisis: lecciones desde el Uruguay y la Argentina”, en Realidad Económica, núm. 225, Buenos Aires, IADE, enero-febrero 2007, pp. 29-45.

Notcheff, Hugo, “¿Existe una política de ciencia y tecnología en la Argentina? Un enfoque desde la Economía Política”, en Desarrollo Económico, Buenos Aires, IDES, vol. 41, núm. 14, enero-marzo 2002, pp. 555-578.

Nochteff, Hugo, "La experiencia argentina: ¿̇desarrollo o sucesión de burbujas?”, en Revista de la CEPAL, núm. 59, agosto 1996, pp. 113-127.

Puente, Ignacio; Etchemendy, Sebastián, "El sector bancario argentino en la globalización: de la extranjerización al resurgimiento de los grupos financieros domésticos", en III Jornadas de Economía Política, Buenos Aires, UNGS, 2009.

Sábato, Jorge, La clase dominante en la Argentina moderna, Buenos Aires, CISEA, 1988.

Soskice, David, "Divergent Production Regimes: Coordinated and Uncoordinated Market Economies in the 1980s and 1990s", en Kitschelt, Herbert; Peter Lange, Gary Marks, John D. Stephens, (eds.), Continuity and Change in Contemporary Capitalism, New York, Cambridge University Press, 1999, pp. 101-134.

Titelman, Daniel, "La banca de desarrollo y el financiamiento productivo", en Serie Financiamiento del desarrollo, núm. 137, Santiago de Chile, CEPAL, octubre 2003.

Wallerstein, Immanuel, Capitalismo histórico y movimientos antisistémicos. Un análisis de sistemas-mundo, Madrid, Akal, 2004. 
Weiss, Linda, "Introduction: Bringing Domestic Institutions Back In", en Weiss, Linda (ed.), States in the Global Economy. Bringing Domestic Institutions Back In, United Kingdom, Cambridge University Press, 2003, pp. 1-36.

Woo-Cumings, Meredith, The Developmental State, New York, Cornell University Press, 1999.

Zysman, John, Governments, Markets, and Growth. Financial Systems and the Politics of Industrial Change, Ithaca and London, Cornell University Press, 1983. 